\section{OUTBREAK OF ENTERIC FEVER THE RESULT OF INFECTED ICE-CREAM.}

BY W. G. BARRAS, M.D. GLASG., L.S.Sc. DuRH., D.P.H., BACTERIOLOGIST TO THE PUBLIC HEALTH DEPARTMENT, GOVAN.

TowARDS the latter half of September a sudden and alarming outbreak of enteric fever occurred within a circum. scribed area of the burgh of Govan, and as its causation was speedily determined a short account of the epidemic may be of interest, especially in view of the proposed legislation with respect to the manufacture and sale of ice-cream.

The sequence of events may be briefly summarised as follows. The first case of the series within this area was reported to the health department upon Sept. 20th, followed by two cases on the 21st, six on the 22nd, four on the 23rd, four on the 24th, and one each on the 27th and 28th respectively. To be strictly accurate, the two latter should be ante-dated to the 20th and 21st respectively, for the usual characteristic clinical manifestations were indefinite, and Widal's reaction in both instances at first gave a negative result, although the reaction was positive when the cases were notified. Both had been ill for at least a week. Excluding the case which undoubtedly gave rise to the outbreak it will be seen that in all there were 19 cases within a period of five days-viz., from Sept. 20th to 24th inclusive. Seeing that they had all occurred within a well-d ned area and that only a few sporadic cases had been reported previously in other parts of the burgh (population 91,000) outside the affected zone, investigations were conducted with a view to eliciting the local cause of the outbreak. Nothing in common as regards the drainage or water-supply of the district could be regarded as the determining factor, but inquiries as to the milk-supply disclosed the fact that 15 of the 20 cases, or 75 per cent. of the total, received their milk, either wholly or in part, from a dairy in the immediate neighbourhood. At the same time it was ascertained that amongst the first cases reported several had recently partaken of ice-cream at a certain shop kept by an Italian also within the affected district and separated only by a few yards from the abovementioned dairy, and that although the ice-cream vendor occasionally used the milk for his own personal consumption from the same source as the majority of the persons attacked, that which entered into the composition of the ice-cream was obtained from a totally different part of the burgh and which was, and still is, entirely free from any similar cases. At this stage the milk was naturally looked upon with grave suspicion, but this was soon dispelled when it was found that the dairyman in question had other three shops in the town all supplied with the same milk, but to which no cases could be attributed, in addition to which it was all "paste mrised" before being retailed or sent out to his customers, with the exception of the morning's delivery which came from two farms in an adjoining county. That the latter also could have no causal relation to the outbreak was shown by the fact that the medical officer of health of the county from which the milk was obtained reported both farms to be in good sanitary condition in every respect and that there had been no recent illness amongst the dairy hands.

As the drainage, water, and milk-supply were thus shown to have absolutely no connexion with the outbreak attention was again directed to the ice-cream shop. When the inspector called to see the proprietor he was informed by the man in charge that he had not been at business for several days on account of illness, and on visiting him at his house, which was just above the shop and entering from a common passage, he was found to be in bed and without medical attendance. This information was immediately communicated to the medical officer of health who upon examination found that the proprietor harl been ailing since Sept. 4th and that he had continued attending to the manufacture and sale of ice-cream in the said premises up to Sept. 15th, since which date he had been confined to the house from what he himself believed to be an attack of "influenza" but which undoubtedly proved to be enteric fever and presented all the characteristic symptoms of the disease met with during the third week of the illness. In order to demonstrate that the disease was unquestionably enteric fever a specimen of his blood was sent to the bacteriological lakoratory here for examination by Widal's reaction. A recent agar growth of the bacillus typhosus was employer in a dilution of 1 in 30 , when agglutination and cessation of movement occurred within half an hour, thus proving beyond a doubt the true nature of the disease. The patient was again visited immediately after the reaction was found to be positive, when he was informed of the result and his shop was at once closed: the stock of ice-cream found on the premises was destroyed, the patient was removed to hospital, and the house and shop were thoroughly disinfected.

The result of further investigation was to show that without exception every one of the other 19 cases had used the ice-cream manufactured in the shop between Sept 4th and 15th inclusive, this being the period during which it had been exposed to infection. As the incubation period of enteric fever lies between the extremes of seven and 21 days the date of sickening in each instance was carefully gone into, the result of which was to show that corresponding to the shortest period within these limits the first case sickened on the 12th, whilst four sickened on the 13th, two on the 14th, eight on the 15th, three on the 17th, and one on the 19th, the extremes being in this outbreak between eight and 15 days, the usual average being regarded as from ten to 14 days. As the above source of infection ceased to be operative after Sept. 15th and as the recognised period of quarantine is 23 days and as this stage has now been passed, it is satisfactory to report that there have been no further cases in this connexion and that the outbreak is at an end.

A similar outbreak on a much larger scale has been recorded by Dr. A. Campbell Munro, medical officer of health of Renfrewshire, in the latter half of 1893.' That enterie fever may be spread by the use of ice and ice-cream has been conclusively shown by the fact that the micro-organisms of the disease have been cultivated after having been frozer in ice for 103 days. " The above facts show the absolute necessity of having all such premises duly licensed and inspected under the Dairies, Cowsheds, and Milk-shops Order, notwithstanding the judgment that an ice-cream vendor in whose business milk forms such an important constituent is held not to be a purveyor of milk (Lang $v$. Pianta, Jan. 22nd, 1894, 21 R. (J.C.) 20 ; 1 S. L. T., 474). Govan.

\section{A CASE OF ACUTE INVERSION OF THE UTERUS ; REDUCTION BY TAXIS ON THE SEVENTH DAY AFTER LABOUR.}

By E. OCTAVIUS CROFT, M.D.DURH., M.R.C.S. ENG., HONORARY SURGEON TO THE HOSPITAL FOR WOMEN AND CHILDRFX, LEEDS ; DEMOXSTRATOR OF OBSTETRICS, UNIVERSITY OF LEEDS.

IN THE LaNcet of June 11th, 1904, p. 1649, I, in ascociation with Mr. R. Mraschamp, fully reported a case of acute inversion of the puerperal nterus in which reduction by taxis was satisfactorily effected on the eighth day of the puerperium. A similar case in which I replaced the uterus on the seventh day having recently come under my care is, I think, worthy of a brief record owing to the rarity of the condition.

The patient, aged 29 years, was delivered of her third child on July 4th, 1904. She was attended by a midwife. There is no sufficiently trustworthy history as to the events which occurred at the time. On the 5th, however, the patient sat up in bed to use the bed-pan and while straining she felt something come down. Severe hæmorrhage took place and a medical man who was sent for discovered the completely inverted condition of the uterus and as a temporary measure plugged the vagina. On the 6th the patient was anæsthetised with ether and a prolonged attempt was made to reduce the inversion. As further attempts might possibly have been harmful it was thought better to desist and to adopt gradual methods. Aveling's repositor was then inserted, but owing to the large size of the uterus it could not be kept in favourable position to be of use. On the 11th, being the seventh day of the puerperium, she

1 Public Health, vol. vii., p. 30

2 Aids to Sanitary Science, by Dr. F. J.'Allan, Medical Officer of Health of Westminster, 1903, p. 193 